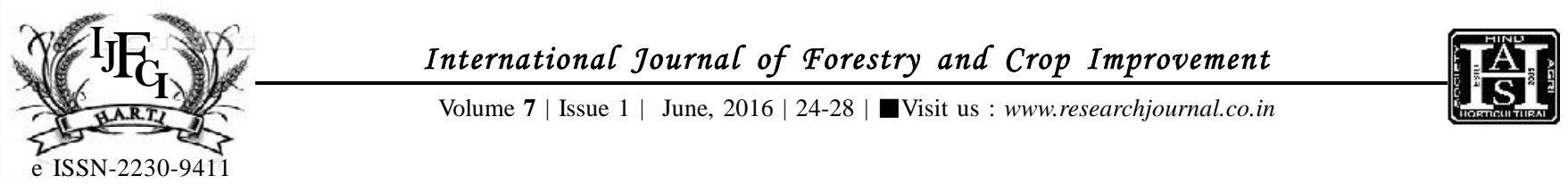

\title{
Evaluation of cultural control practices in the management of sweet potato weevil (Cylas formicarius) (Apionidae : Colepotera)
}

\author{
M. DEVI, R. F. NiRANJANA AND N. KALIESWARI
}

\begin{abstract}
The sweet potato weevil, Cylas formicarius, constitutes a major constraint to sweet potato production and utilization in Africa. Host plant resistance/tolerance, mulching and varying harvesting dates could provide an approach that fits well into an integrated pest management programme of this insect pest. In this study, a trial was conducted to evaluate the effect of host plant, mulching with freshly harvested, dried and chopped up aerial parts of elephant grass (Panicum maximum), and the manipulation of harvesting date, on crop damage by the sweet potato weevil. Cylas formicarius incidence was observed to decrease with increase in mulching level. Also, significant cultivar variation with respect to Cylas formicarius tuber damage and the total number of tubers produced were recorded. Karur local (White) and Arun (White) were observed to be significantly less susceptible to the sweetpotato weevil. Harvesting date was also significantly different, with respect to the number of damaged tubers. More tubers were damaged when harvesting was delayed. Hence, using Karur local (White) or Arun (White), coupled with mulching at the rate of 3-5t/ha and harvesting at 104 DAP resulted in increased number of tubers and reduced sweetpotato weevil infestation in the field.
\end{abstract}

KEY WORDS : Cylas formicarius, Sweet potato, Mulching, Harvesting date, Tuber damage

How TO CITE THIS ARTICLE : Devi, M., Niranjana, R.F. and Kalieswari, N. (2016). Evaluation of cultural control practices in the management of sweet potato weevil (Cylas formicarius) (Apionidae : Colepotera). Internat. J. Forestry \& Crop Improv., 7 (1) : 24-28, DOI: 10.15740/HAS/IJFCI/7.1/24-28.

ArTiCle ChroniCAL : Received : 18.02.2016; Revised : 06.04.2016; Accepted : 07.05.2016 